\title{
Investigação e Paradoxo do Mênon: Aristóteles, Segundos Analíticos II 8
}

\author{
David Bronstein \\ University of Boston/ University of 0xford (Balliol College) \\ davidjbronstein@gmail.com
}

resumo Este artigo discute certos problemas que aparecem na teoria aristotélica da investigação científica no capítulo 8 do livro II dos Segundos Analíticos de Aristóteles. Aristóteles distingue três estágios de investigação científica. Meu ponto é que a teoria aristotélica da investigação científica consegue evitar o paradoxo de Mênon - sobre a impossibilidade de qualquer investigação - apenas se o segundo estágio reconhecido por Aristóteles, o estágio em que se estabelece que o objeto existe, for entendido como estágio em que se estabelece que o objeto em questão existe a título de explanandum legítimo no domínio de uma dada ciência.

palavras-chave epistemologia; investigação científica; definição; explicação; aprendizado; heurística

\section{Introdução}

Segundos Analíticos (daqui em diante, APo) II 8 é um dos capítulos mais dificeis e mais importantes da obra de Aristóteles. Ele é importante porque explica como se investiga e se adquire conhecimento da essência de algo. Ele é difícil porque, tal como a maior parte dos $A P$, alguns trechos beiram o ininteligível, e é dificil discernir a estrutura e o significado filosófico do capítulo como um todo. Meu objetivo neste artigo consiste em tentar mostrar que a concepção de investigação que Aristóteles propõe em $A P o$ II 8 é inteligível e filosoficamente interessante, o que farei argumentando que o capítulo pode ser mais bem entendido como 
uma resposta a uma versão específica do paradoxo de Mênon, que aparecera em APo II 1-2. O paradoxo de Mênon, proveniente do Mênon de Platão, é o famoso argumento de acordo com o qual é aprendizado e investigação são impossíveis: não se pode procurar saber aquilo que já se sabe (pois já se sabe, de modo que não há nenhuma necessidade de procurar), nem aquilo que não se sabe (pois não se sabe o que se deve procurar) (Mênon 80d5-e5). Outros comentadores detectaram signais do paradoxo de Mênon em APo II 1-2 e 8. ${ }^{1}$ No entanto, eles deixaram de captar dois pontos importantes. Primeiro, a versão de Aristóteles para o impasse diz respeito à possibilidade de investigar se algo existe (mas não, como freqüentemente se supõe, o que algo é). ${ }^{2}$ Segundo, Aristóteles oferece em $A$ Po II 8 três soluções para o impasse - três caminhos para o conhecimento de que algo existe. Começarei meu argumento delineando o impasse que emerge de $A P o$ II 1-2 e, a seguir, avançarei para as três soluções expostas em II-8.

\section{Três estágios de investigação}

Em APo II 1-2, Aristóteles distingue dois conjuntos de questões envolvidas na investigação científica: questões de existência e questões de causa ou essência (89b 23-5). Questões de existência incluem "a lua sofreu eclipse?” ou "eclipse existe?", “deus existe?” e assim por diante (89b 26, 32). Questões de causa ou essência incluem "por que a lua sofreu eclipse?” e "o que deus é?” (89b 29-31, 34-5). Além disso, Aristóteles diz que as questões "por que" e "o que é" são idênticas (90a 14-23), bem como são o mesmo conhecer o porquê e conhecer o que é (90a 31-4, 93a 3-4). Consideremos um de seus exemplos favoritos: o eclipse. Em II2, Aristóteles diz que "o que eclipse é" é privação de luz na lua devido à sombra produzida pela Terra, bem como diz que a razão pela qual ocorre eclipse é que a luz está ausente da lua quando a Terra projeta sua sombra (90a 15-8). O "que é" e o "por que", a essência e a causa, são idênticos.

Em APo II 1-2 Aristóteles introduz também importante tese sobre a ordem temporal da investigação. Primeiramente, investigamos se algo existe; depois, investigamos qual é sua causa ou sua essência - por exemplo, primeiramente apreendemos que a lua se eclipsou e, então, procu- 
ramos a razão disso (89b 29-31, 34-5). ${ }^{3}$ À parte alguns casos excepcionais (um dos quais discutirei logo mais), a regra geral é que devemos conhecer que $\mathrm{x}$ é antes de podermos procurar o que $x$ é ou por que $x$ é. Observe-se que, para Aristóteles, a existência de uma coisa é um genuíno objeto de investigação, é algo que devemos apreender.Voltarei a esse ponto logo mais.

O resultado dessas teses de Aristóteles é um quadro geral sobre a investigação científica eficaz, de acordo com o qual, como David Charles argumentou, a investigação é dividida em três estágios: ${ }^{4}$

- no estágio 1, o investigador não conhece ou sabe que $x$ existe, nem conhece sua causa ou essência, mas investiga se $x$ existe.

- no estágio 2, o investigador conhece ou sabe que $x$ existe, mas não conhece sua causa ou essência, e investiga o que essa causa ou essa essência é.

- no estágio 3, o investigador conhece ou sabe que x existe, bem como conhece o que sua causa ou sua essência é - sua investigação está completa.

Como veremos logo mais, em APo II 8 Aristóteles opera com esse quadro que concebe a investigação de acordo com três estágios. Mas, por enquanto, examinemos mais detalhadamente como ele apresenta os dois primeiros estágios em APo II 2. Bem no início de II 2 Aristóteles dá um passo crucial e embaraçoso, ao dizer que investigar se um objeto existe é o mesmo que investigar se tal objeto tem uma causa ou uma explicação (aition) (89b 37-90a 8). Assim, por exemplo, investigar se a lua sofreu eclipse consiste em investigar se há uma causa ou explicação do fato de que a lua sofre eclipse. Assim que sabemos que há uma causa, procuramos saber o que essa causa é. Dado que a causa é o mesmo que a essência (como já vimos), podemos formular o ponto de Aristóteles do seguinte modo: começamos nossa investigação ao procurar saber se há uma essência. Chamemos esse ponto de "requisito causal" da questão sobre existência. Esse requisito causal nos diz algo importante a respeito dos dois primeiros estágios de investigação. No estágio 1, investigar se $\mathrm{x}$ existe consiste em investigar se uma causa ou uma essência de x existe. No estágio 2, saber que $\mathrm{x}$ existe consitste em saber que uma causa ou uma essência de $\mathrm{x}$ existe, sem saber o que essa causa ou essência é. $\mathrm{Na}$ passagem do estágio 2 para o estágio 3, o investigador apreende o que 
essa causa ou essência é. Esse requisito causal é importante por outra razão também. Ele torna claro que, quando investigamos se x existe, não estamos investigando se existem xs, nem estamos investigando se isto ou aquilo é um x. Estas questões fazem parte da investigação, sem dúvida, mas o objetivo do investigador é determinar se $\mathrm{x}$, como um tipo de coisas, existe. ${ }^{5}$ Pois, na visão de Aristóteles, apenas tipos têm causas ou essências, propriamente falando.

\section{A versão do paradoxo de Mênon em APo II 2}

O requisito causal é tão importante quanto surpreendente. De fato, devese indagar como eventualmente poderíamos investigar se há uma causa ou uma essência do modo pelo qual a tese de Aristóteles requer. Considere-se a seguinte analogia. Alguém solicitou que procurássemos saber se uma dada pessoa, Keren, existe. Nessa circunstância, precisaríamos de uma descrição de Keren suficiente para iniciar tal procura. Poderíamos dizer que precisaríamos saber quem é Keren, antes de poder investigar se ela existe. Imaginemos, porém, que alguém nos dissesse que não poderíamos conhecer quem Keren é até que descobríssemos que ela existe. Nessa circunstância, teríamos grande dificuldade para começar nossa investigação: o presumido ponto de partida (quem é Keren) pressupõe o fim que se procura (que Keren existe). ${ }^{6}$ Parece surgir uma dificuldade similar com relação à tese de Aristóteles sobre os estágios da investigação científica. De acordo com essa tese, devemos conhecer que existe uma causa ou essência do eclipse (por exemplo) antes de poder investigar o que essa causa ou essência é. Mas parece que também devemos conhecer o que essa causa ou essência é para poder investigar se ela existe. Caso contrário, como poderíamos conhecer o que estamos a investigar?7 Parafraseando Mênon, como poderíamos investigar se uma causa ou essência existe, quando de modo algum sabemos o que ela é? Qual das causas ou essências que não conhecemos deveríamos estabelecer como alvo de nossa investigação? E se ocorrer que deparemos com ela, como poderíamos saber que ela é a causa ou essência cuja existência estávamos a investigar? ${ }^{8}$ Além disso, se já conhecemos o que essa causa ou essência é, não mais precisamos investigar se ela existe. ${ }^{9}$ Pois, de acordo 
com a teoria de Aristóteles sobre os estágios da investigação, segue-se imediatamente que, se sabemos o que essa causa ou essência é, devemos já ter apreendido que ela existe. Em suma, a teoria de Aristóteles sobre a investigação em $A P o$ II 1-2 faz surgir certa versão do paradoxo de Mênon que ameaça a possibilidade de investigar se algo existe. Eis o impasse, em formulação mais precisa:

(1) Se já sabemos o que a causa ou essência de $x$ é, não podemos investigar se a causa ou essência de $x$ existe (pois, nessa circunstância, já devemos conhecer que tal causa ou essência existe).

(2) Se ainda não sabemos o que a causa ou essência de $x$ é, não podemos investigar se a causa ou essência de $x$ existe (pois, nessa circunstância, não sabemos o que devemos procurar).

(3) Por conseguinte, não podemos investigar se existe uma causa ou essência de $x$.

(4) Investigar se existe uma causa ou essência de $x$ é o mesmo que investigar se $x$ existe (pelo "requisito causal").

(5) Por conseguinte, não podemos investigar se $x$ existe. ${ }^{10}$

Esse argumento depende de uma pressuposição suplementar: a de que o conhecimento da causa ou da essência é do tipo "tudo ou nada".

(6) Antes de investigar se existe uma causa ou essência de $x$, ou conhecemos completamente ou não conhecemos de modo algum o que a causa ou essência de $x$ é.

Esse argumento tem, com certeza, uma falha - pois a premissa (6) parece-nos, como certamente se teria afigurado a Aristóteles, ser extremamente duvidosa - mas não é desprovido de valor. Meu ponto é que um impasse desse tipo dá forma ao que Aristóteles argumenta em $A P o$ II 8 de um modo que os especialistas não perceberam. Duvido que Aristóteles tenha se perturbado em algum momento com qualquer versão do paradoxo do Mênon. As evidências - o fato óbvio de que nós de fato investigamos e aprendemos - contam muito fortemente contra o paradoxo. Mesmo assim, versões do paradoxo implicitamente animam várias discussões nos $A P o$, fornecendo uma perspectiva útil na qual a concepção aristotélica de aprendizado torna-se clara. APo II 8 contém uma dessas discussões. ${ }^{11}$ 


\section{Por que há o requisito causal sobre a questão de existência?}

Acabei de formular um impasse sobre como podemos investigar se algo existe no sentido de que possui uma causa ou essência. Mas podemos também indagar o que significa conhecer que algo existe nesse sentido. Antes de tudo, trata-se de uma idéia desconcertante: como podemos saber que existe uma causa ou essência de $x$ sem saber $o$ que a causa ou essência de $x$ é? Além do mais, por que Aristóteles julga que precisamos conhecer que $x$ existe nesse sentido preciso?

Nessa juntura, é útil notar que, para Aristóteles, o alvo da investigação é o conhecimento científico (epistêmê), que ele restringe a um leque limitado de objetos. A ciência lida com as causas das coisas, mas não é tudo que tem uma causa no sentido propriamente aristotélico - a saber, o tipo de causa que é idêntico a uma essência. ${ }^{12}$ Coisas que existem por acaso não têm causas nesse sentido. ${ }^{13}$ As únicas coisas que têm causas desse tipo, e as únicas coisas que podem ser conhecidas cientificamente, são as coisas que existem "sempre ou no mais das vezes". ${ }^{14}$ Podemos formular esse ponto de um modo diferente: para Aristóteles, não é tudo que conta como explanandum. Coisas que existem por acaso não são explananda. E esse ponto é importante, pois significa que, em estágios iniciais de uma investigação, é uma questão genuína saber se o objeto que se investiga é um explanandum ou não. E tem-se uma autêntica conquista epistêmica, quando se compreende que algo é, de fato, um explanandum. É esse ponto que Aristóteles tem em mente quando introduz o requisito causal na questão de existência. A seus olhos, saber que $x$ tem uma causa, no estágio 2, sem saber o que essa causa ou essência é consiste em saber que $x$ é um explanandum no domínio da ciência em questão ${ }^{15}$ - i.e., que $x$ existe não por acaso, mas sempre ou no mais das vezes. ${ }^{16}$ Isso também explica por que, afinal, Aristóteles introduz o requisito causal: esse requisito funciona como um critério que permite ao investigador, no domínio de uma dada ciência, excluir de seu campo de investigação os objetos que não são suscetíveis ao conhecimento científico. Em suma, precisamos de dois pontos adicionais sobre os estágios de investigação, pontos que ajudarão a esclarecer a teoria de Aristóteles em $A P o$ II 8 . No estágio 1, investiga-se se $x$ é um explanandum; no estágio 2, já se sabe que $x$ é um explanandum sem se saber o que a causa ou explicação de $x$ é. 


\section{Prospecto geral de APo II 8}

O contexto imediato de $A P o$ II 8 gira em torno de uma questão técnica: uma essência ou definição pode ser demonstrada (93a 1-3)? Aristóteles responde de modo típico: em certo sentido, sim, em outro sentido, não. Uma demonstração é um tipo especial de silogismo cujas premissas são, entre outras coisas, a explicação da conclusão. Uma definição, por sua vez, enuncia a essência de uma dada coisa. Por exemplo:

Eclipse é (df.) privação de luz na lua devido à interposição da Terra.

A concepção de Aristóteles é que essa definição não pode ser demonstrada, no sentido de que ela não pode ser deduzida como uma conclusão de premissas que a explicassem. Definições são primeiros princípios e, enquanto tais, são indemonstráveis. Mas, mesmo assim, Aristóteles sugere, em $A P_{0}$ II 8, haver um outro aspecto, pelo qual a essência poderia ser demonstrada. Se tomamos apenas os termos do definiens, sem tomar o termo definiendum (eclipse), podemos ordená-los de tal modo que eles venham a configurar uma demonstração, a qual revelará o que é a essência do eclipse, sem, no entanto, prová-la na conclusão. Como Aristóteles diz no final de $A P_{0}$ II 8, embora não haja demonstração de uma essência, podemos vir a conhecer uma essência através de uma demonstração (93b 15-8). Esse ponto é relativamente incontroverso. Mais controverso e especialmente difícil é entender como Aristóteles julga que um investigador eventualmente alcança esse tipo de demonstração. Minha opinião é a seguinte. No final de $A P_{0}$ II 8, Aristóteles diz que essa demonstração que revela a essência é o meio pelo qual o investigador aprende o que uma dada essência é (93b 15-20). Em outras palavras, essa demonstração representa a passagem do estágio 2 para o estágio 3. No entanto, como vimos em nossa discussão do paradoxo do Mênon, Aristóteles precisa explicar como passamos do estágio 1 para o estágio 2 - como apreendemos que o eclipse existe, no sentido de que ele tem uma essência. Acredito que boa parte de $A P_{0}$ II 8 é dedicada a explicar exatamente esse ponto. Assim, ainda que o objetivo oficialmente declarado de $A P_{0}$ II 8 seja mostrar como chegamos ao estágio 3, Aristóteles dedica boa parte do capítulo a mostrar como alcançamos o estágio 2 - este ponto, em favor do qual argumentarei, é algo que os comentadores freqüentemente deixaram 
escapar. ${ }^{17}$ Aristóteles, a rigor, proporá três diferentes caminhos para o estágio 2 e, portanto, três diferentes soluções para o paradoxo de Mênon.

\section{Primeiro caminho para o conhecimento, primeira solução}

Como pela primeira solução, que ocorre quase no final de $A P o$ II 8. Depois de certas observações preliminares que assentam o contexto do capítulo, Aristóteles diz o seguinte:

T1 [i] De que modo é possível [demonstrar a essência], digamo-lo, considerando novamente desde o começo. Tal como procuramos o porquê assim que dispomos do que, e, embora às vezes ambos se tornem evidentes ao mesmo tempo, não é possível vir a conhecer por que antes do que, evidentemente, de modo semelhante, tampouco é possível vir a conhecer o "o que algo é [a essência]" sem conhecer "que existe"; pois é impossível saber o "o que é", ignorando se existe. [ii] O "se existe", às vezes apreendemo-lo por um concomitante, às vezes, porém, apreendendo algo do próprio objeto; por exemplo, com relação ao trovão, que ele é certo estrondo nas nuvens, e que o eclipse é certa privação de luz, e que o homem é certo animal, e que a alma é aquilo que se move a si mesmo. [iii] Com relação a tudo que conhecemos que existe por um concomitante, é necessário que não tenhamos conhecimento do "o que é"; pois nem sequer sabemos que existe; e procurar o "o que é" sem ter apreendido que existe consiste em nada procurar. Mas, para todos os casos em que apreendemos algo [do objeto], a investigação é mais fácil. Resulta disso que o modo pelo qual apreendemos que existe determina até que ponto podemos apreender o "o que é". 18 (93a 15-29). ${ }^{19}$

Em T1[i], Aristóteles estabelece três estágios de investigação, focando especialmente o estágio 2, no qual o investigador conhecer que um dado objeto existe e procura saber o que sua essência é. $\mathrm{Na}$ seção [ii], ele contrasta dois modos de apreender que um dado objeto existe: por um concomitante, ou quando apreendemos "algo do objeto em si mesmo". $\mathrm{Na}$ seção [iii], ele desenvolve esse ponto sugerindo que a apreensão de "algo do objeto" facilita a investigação. A seção [ii] e outros textos em 
APo II 8 (especialmente 93a 29) indicam que, por "apreender algo do objeto", Aristóteles quer dizer "apreender parte de sua essência”. Um de seus exemplos na seção [ii] é a apreensão de que o eclipse é certa privação de luz, e sabemos que "privação de luz" é parte da essência do eclipse. ${ }^{20}$ Aristóteles julga que ter esse conhecimento põe-nos em condições de aprender a essência. Ele parece querer dizer que, quando conhecemos parte da essência, podemos procurar e aprender a essência completa.

Até então, o argumento de Aristóteles concentra-se em como passamos do estágio 2 ao estágio 3, como aprendemos uma essência. Mas essa seção também nos fornece condições para explicar como passamos do estágio 1 para o estágio 2 - como aprendemos que algo existe - e, ao fazê-lo, o faz de tal modo que evita o paradoxo de Mênon. O núcleo do argumento de Aristóteles é a afirmação de que podemos apreender parte da essência de uma dada coisa, o que nega a pressuposição que subjaz ao impasse: a pressuposição de que conhecer uma essência se dá como "tudo ou nada". Para compreender esse ponto, precisamos interpretar o argumento de Aristóteles de modo bem amplo. Em alguns casos, conhecer parte de uma essência consiste em conhecer que $A$ é parte da essência $E$ sem conhecer as outras partes de $E$. Nessas circunstâncias, o investigador estaria no estágio 2, pois conheceria que a essência $E$ existe. (Aristóteles parece ter essas circunstâncias em mente, nas seções [ii] e [iii]). Em outros casos, conhecer parte de uma essência consiste em conhecer que, por exemplo, privação de luz é uma propriedade do eclipse, uma propriedade que vem a ser parte da essência, mas que não é conhecida como parte da essência do eclipse. Nessas circunstâncias, o investigador pode estar no estágio 1, pois é possível apreender uma propriedade do eclipse - uma propriedade que virá a ser parte de sua essência - sem ainda apreender que há uma essência a ser apreendida. Em outras palavras, o investigador tem aquilo que poderíamos chamar de compreensão preliminar do estágio 1: conhece que, se existe eclipse, eclipse é uma privação de luz na lua. ${ }^{21}$ É nisso que reside a solução do paradoxo de Mênon. O investigador não sabe se o eclipse existe no sentido relevante, nem conhece o que sua essência é (ou seja, está no estágio 1). Mesmo assim, ele conhece o suficiente sobre o eclipse para iniciar sua investigação. $\mathrm{Na}$ feliz expressão de Charles, sua compreensão preliminar funciona como um "trampolim" para sua investigação sobre a existência do eclipse. ${ }^{22}$ 
Vejamos como a pesquisa desse investigador procederia. Sua compreensão preliminar identifica eclipse com um determinado fenômeno observável. Conseqüentemente, ele pode vir a conhecer que existe eclipse observando casos em que a lua sofre o tipo relevante de privação de luz, ou recolhendo testemunhos confiáveis para tal efeito. Quando ele tiver recolhido dados suficientes, estará apto a construir a seguinte prova silogística:

Eclipse ocorre a privação de luz.

Privação de luz ocorre à Lua.

Logo, eclipse ocorre à Lua.

Aristóteles não formula esse silogismo em $A P o$ II 8, embora, como logo mais veremos, ele é muito similar aos outros silogismos que Aristóteles de fato apresenta nesse capítulo. Segue-se minha tentativa de reconstruir, com base no texto T1, a teoria de Aristóteles sobre a passagem do estágio 1 para o estágio 2.

A conclusão desse silogismo estabelece para o investigador que o eclipse existe (ou que a lua sofre eclipse). Mas - este é o ponto-chave esse silogismo também revela que o eclipse é um explanandum. De fato, o investigador identifica eclipse com a privação de lua na Lua, é é isso que requer explicação. Dado que a lua cheia perde sua luminosidade com certo grau de regularidade, o investigador infere que não se trata de um evento casual. Daí, ele percebe que esse evento deve ter uma causa, embora não saiba ainda o que essa causa é. Dada a identidade entre causa e essência, ele sabe que o eclipse tem uma essência - e, portanto, sabe que o eclipse existe no sentido relevante. ${ }^{23}$ Ele fez a passagem do estágio 1 para o estágio 2, de modo a evitar o paradoxo de Mênon. Sua concepção preliminar no estágio 1 é suficientemente específica para lhe permitir investigar, embora não seja tão específica a ponto de exaurir a essência inteira do eclipse. Aristóteles dispõe dessa solução porque ele nega, de modo convincente, a idéia (filosoficamente pouco atrativa) de que conhecer a essência é uma questão de tudo ou nada. Se, como Aristóteles afirma, podemos conhecer parte de uma essência - sem conhecê-la enquanto parte de uma essência, sem mesmo saber que há uma essência -, há como prosseguir na investigação. 


\section{A demonstração que revela a essência: do estágio 2 ao estágio 3}

Vejamos então como o investigador chega ao estágio 3, como ele vem a conhecer o que a essência do eclipse é. Munido com o silogismo acima introduzido, o investigador tem um alvo determinado para sua pesquisa: a causa pela qual a Lua perde sua luminosidade - ou seja, o termo médio, ou termo explanatório, que liga "Lua" e "privação de luz", termos apresentados na premissa menor do mencionado silogismo. ${ }^{24} \mathrm{Se}$ sua pesquisa for bem sucedida, ele descobrirá que a causa é o fato de a Terra proteger a Lua da luz do sol. Ele estará apto, então, a construir a seguinte demonstração:

Privação de luz se atribui a ser encoberta pela Terra.

Ser encoberta pela Terra se atribui à Lua.

Logo, privação de luz se atribui à Lua.

Quanto a este silogismo, Aristóteles de fato estabelece seus termos claramente em $A P_{0}$ II 8.25 (Nessa altura ao texto, o exemplo muda para trovão, mas o paralelismo com o caso do eclipse é suficientemente claro para garantir as substituições requisitadas). Trata-se, agora, de uma demonstração, não de um mero silogismo, porque o termo médio ("ser encoberta pela Terra”) estabelece a causa da relação entre sujeito e predicado expressa na conclusão. Resulta disso que, tomando a demonstração como um todo, pode-se "ler", como Barnes disse, ${ }^{26}$ a essência completa do eclipse: privação de luz na Lua devido ao encobrimento pela Terra. É nesse sentido que a demonstração revela a essência, sem prová-la, porém. A essência como um todo não aparece na conclusão, mas aparece como relação causal expressa na demonstração em seu todo. ${ }^{27}$ Observe-se, no entanto, que a conclusão é "privação de luz se atribui à Lua". Ora, essa sentença representa a concepção preliminar do investigador no estágio 1. Essa sentença era, também, a premissa menor do silogismo no estágio 2. Que ela seja também a conclusão de sua demonstração no estágio 3 é exatamente o que se deveria esperar, dado que se trata do explanandum que é alvo da pesquisa em busca de uma causa. ${ }^{28}$ A privação de luz na Lua é o explanandum. Ser encoberta pela Terra é o explanans. Juntos, eles constituem a essência completa do eclipse, cujo conhecimento pode ser 
alcançado, como diz Aristóteles, apenas pela demonstração que o revela (93a 15-20).

No entanto, se poderia objetar o seguinte: o investigador sabe que a conjunção dessas duas propriedades é a essência do eclipse? Como ele poderá saber que encontrou o que estava a procurar? A resposta que sugiro reside na concepção aristotélica de concomitante per se (kath' hauto sumbebekos) - as propriedades necessárias, mas não essenciais, que são explicadas pela essência daquilo a que se atribuem. De fato, eles fornecem um meio para julgar a adequação de uma presumida essência: se ela explica todos os concomitantes per se de algo e não é explicada por nenhum deles, certamente se trata da essência da coisa em questão. Assim, o investigador saberá que a conjunção daquelas duas propriedades configura a essência do eclipse quando a testar em confronto com os concomitantes per se. De todo modo, é isso que Aristóteles nos diz em De Anima I 1:

T2 "os concomitantes contribuem em grande parte para o conhecimento do 'o que é'; quando podemos, de acordo com as evidências, discorrer a respeito dos concomitantes, ou de todos eles, ou da maioria, então também a respeito da essência podemos dizer algo da maneira mais acertada" 29 (402b 21-5).

Como veremos abaixo, Aristóteles explicitamente usa essa concepção, quando estabelece o terceiro caminho para o conhecimento. De fato, é interessante notar como sua teoria do conhecimento científico sutilmente combina posições que nos habituamos a manter separadas. $\mathrm{Na}$ medida em que o conhecimento é fundamentado na apreensão de primeiros princípios indemonstráveis (especialmente definições, que expressam essências), Aristóteles pode ser caracterizado como um fundacionalista. Mas, na medida em que a aquisição do conhecimento de uma essência requer a compreensão de seu papel explanatório em uma rede articulada de verdades que constituem uma ciência, sua posição contém significativamente elementos de coerentismo. ${ }^{30}$

Esse ponto completa minha interpretação sobre o primeiro caminho através dos três estágios de investigação. Uma razão para julgar que minha interpretação está correta é que o investigador segue aquilo que Aristóteles julga ser a trajetória comum de todo aprendizado. Aprender sempre começa com aquilo que é mais familiar ou inteligível para nós, com aqui- 
lo que está mais próximo de nossa experiência perceptiva, e termina naquilo que é mais inteligível por natureza, naquilo que é mais afastado de nossa experiência perceptiva. ${ }^{31}$ É essa a trajetória do investigador: da apreensão da privação de luz na Lua à apreensão de que a Lua é encoberta pela Terra.

\section{Segundo caminho para o conhecimento, segunda solução}

Vejamos agora a passagem em que Aristóteles esboça um segundo caminho em direção ao conhecimento e uma segunda solução do paradoxo do Mênon (essa passagem vem imediatamente depois de T1):

T3 [i] No que respeita às coisas das quais apreendemos algo do "o que é", seja primeiramente deste modo: seja eclipse $A$, lua $C$, interposição da Terra B. [ii] Assim, “ocorre eclipse, ou não?” é procurar por $B$, “ $B$ é o caso, ou não?”. E em nada difere procurar por isso e procurar saber se há alguma explicação dele [sc. do eclipse]; e se isso [i.e. essa explicação] for o caso, diremos que também aquilo [i.e. o eclipse] é o caso. [...] [iii] Quando descobrimos [que o eclipse existe], conhecemos ao mesmo tempo o "que" e o "porquê", se for através de imediatos; caso contrário, conhecemos o "que", mas não o "porquê". 32 (93a 29-37).

Esse é um texto extremamente difícil. Começarei por um prospecto. $\mathrm{Na}$ seção T3[i], Aristóteles estabelece os termos de uma demonstração cuja conclusão é que existe eclipse (ou que a Lua sofre eclipse). É relativamente consensual que, na seção [ii], ele discute como um investigador vem a conhecer que um eclipse existe. Também é claro que, na seção [iii], Aristóteles contrasta dois casos: no primeiro caso, alguém vem a conhecer ao mesmo tempo que e por que existe eclipse; no segundo caso, alguém vem a conhecer apenas que ele existe, sem conhecer por quê. A principal pergunta que devemos fazer a respeito desse texto consiste na seguinte: como alguém vem a conhecer que o eclipse existe? Ou seja, como devemos interpretar a seção T3[ii]?

Pela seção [ii], é claro que o investigador encontra-se no estágio 1: dado que Aristóteles está a descrever como alguém descobre que o eclipse existe, não pode ser o caso que o investigador já saiba que existe eclipse. ${ }^{33}$ Isso quer dizer que o investigador dispõe de certa concepção 
preliminar sobre o eclipse. Sabemos que a essência completa do eclipse é "privação de luz na Lua devido ao encobrimento pela Terra". No texto T1, Aristóteles mencionara uma noção preliminar, que nomeava parte da essência: privação de luz. É natural supor que, no texto T3, ele menciona outra: o encobrimento pela Terra. Antes de tudo, essa é uma das partes da essência, é "algo do o que é do eclipse" (93a 29). Conseqüentemente, proponho que, de acordo com o texto T3, o investigador no estágio 1 sabe que o eclipse, se existe, é o encobrimento pela Terra. ${ }^{34}$

Considerando o que acabou de ser dito, vejamos novamente a seção T3[ii]. Ofereço a seguinte paráfrase: para investigar se existe ou não eclipse, o investigador deve procurar saber se existe ou não encobrimento pela Terra, o que significa procurar saber se a Lua de fato sofre encobrimento pela Terra. Isso não é diferente de procurar saber se a seguinte definição do eclipse, "encobrimento pela Terra", aplica-se ao sujeito relevante, ou seja, à Lua. Se a definição se aplica, então existe eclipse. E, em tal circunstância, o investigador pode construir a demonstração à qual Aristóteles se reporta na seção [i]:

Eclipse se atribui encobrimento pela Terra.

Encobrimento pela Terra se atribui à Lua.

Eclipse se atribui à Lua.

Em outras palavras, estou a sugerir que, para Aristóteles, compreender a definição preliminar "encobrimento pela Terra" é suficiente para vir a saber que o eclipse existe do mesmo modo que comprender a definição "privação de luz" o é. Aristóteles está a oferecer um segundo caminho em direção ao conhecimento de que existe eclipse. Na seção [iii], ele finalmente indica que esse modo de aquisição de conhecimento é excepcional, pois a definição preliminar já identifica a causa eficiente do eclipse: encobrimento pela Terra. Quando o investigador apreende que a Lua é encoberta, ele apreende não só que mas também por que o eclipse existe. Por essa razão, seu aprendizado é diferente do primeiro caminho para o estágio 2, no qual ele vem a conhecer apenas que o eclipse existe, sem conhecer por quê.

Trata-se de um caminho ímpar para o estágio 2. De fato, podemos indagar o seguinte: afinal, que tipo de definição preliminar é "encobrimento pela Terra"? A definição "privação de luz" parecia ser um bom 
ponto de partida porque identificava algo mais familiar para nós, algo mais próximo de nossa experiência perceptual. Mas "encobrimento pela Terra" não satisfaz esses critérios. Quem, afinal, poderia iniciar uma investigação sobre o eclipse a partir de uma tal definição? Acredito que a resposta é que ninguém poderia - ao menos ninguém na face da Terra. Uma passagem de $A P_{0}$ II 2 esclarece o que Aristóteles tem em mente:

T4: se estivéssemos na Lua, não investigaríamos nem se ocorre, nem por que ocorre, mas seria evidente [que e por que] ao mesmo tempo. Pois nos sucederia conhecer o universal por ter percebido. Pois a sensação é de que agora se interpõe [a Terra] (também seria evidente que agora se eclipsa [a lua]); e a partir disso surgiria o universal. ${ }^{35}$ (90a 26-30)

Aristóteles propõe a seguinte situação: imaginemos que estamos na Lua durante um eclipse. Apreenderíamos imediatamente que e por que há um eclipse, pois poderíamos ver que a Terra se interpõe entre o Sol e a Lua, e isso é a causa eficiente. Minha proposta é que, em T3, Aristóteles se refere a essa situação imaginária. Para habitantes da Lua, "interposição da Terra" seria a definição preliminar de eclipse. Na Terra, "privação de luz" é mais familiar para nós, mais próximo da percepção, de modo que faz sentido para nós iniciar a investigação com uma tal definição preliminar. Mas, na Lua, a situação se reverte: "interposição da Terra" é mais familiar para o habitante da Lua e mais próximo à experiência perceptual dele.É natural para Aristóteles supor que, se estivéssemos na Lua durante um eclipse, a primeira coisa que notaríamos seria a Terra se interpondo entre o Sol e a Lua, mas não que a Lua, tal como vista da Terra, está a perder sua luminosidade. Conseqüentemente, faz sentido, para astrônomos que habitassem a Lua, começar a investigação sobre o eclipse tomando "encobrimento pela Terra" como definição preliminar.

Há uma clara conexão entre T3 e T4: ambos os textos discutem um caso de aprendizado em que simultaneamente se vem a conhecer que e por que a Lua sofre eclipse. E se interpretarmos T3 à luz de T4, podemos dar sentido a um texto que, de outro modo, seria desnorteante. Essa intepretação também nos dá uma visão filosoficamente satisfatória. Aristóteles está a discutir um segundo caminho em direção ao conhecimento da existência e da essência, um caminho que também evita o paradoxo de Mênon. O conhecimento que o habitante da Lua tem no está- 
gio 1 não é tão rico que já incluísse o conhecimento completo da existência e da essência do eclipse, mas é rico o suficiente para fazê-lo entender que o eclipse existe. Mas tal conhecimento desempenha esse papel de modo excepcional, pois o habitante da Lua ao mesmo tempo vem a conhecer por que existe eclipse, de modo que ele dá um só passo do estágio 1 para os estágios 2 e 3 . Além do mais, embora esse segundo caminho possa parecer imaginoso, ele contém uma importante lição filosófica. Os pontos de partida para uma dada investigação, fundados na experiência perceptual, podem variar de pessoa para pessoa. Mesmo assim, visto que uma investigação almeja alcançar o conhecimento de uma essência, que existe no mundo independentemente da experiência, o fim da investigação é o mesmo para todos.

As duas primeiras soluções para o paradoxo do Mênon têm em comum o seguinte: ambos consistem em negar a pressuposição de que conhecer uma essência se dá em termos de "tudo ou nada". O investigador começa com uma definição preliminar, a qual identifica uma propriedade do eclipse (uma propriedade que se tornará parte de sua essência) e fornece recursos suficientes para iniciar a pesquisa. Dado que a essência do eclipse tem duas partes, há duas definições preliminares diferentes. Daí, há também dois diferentes caminhos - mas para o mesmo ponto de chegada.

\section{Terceiro caminho em direção ao conhecimento, terceira solução}

O terceiro caminho em direção ao conhecimento começa com um tipo de definição preliminar que é totalmente diverso. Vejamos a passagem relevante, que é contígua a T3:

T5 [i] Quando descobrimos [que o eclipse existe], conhecemos ao mesmo tempo o "que" e o "por que", se for através de imediatos; caso contrário, conhecemos o "que", mas não o "por que". [ii] Lua $C$, eclipse $A$, não ser capaz de fazer sombra no plenilúnio, não havendo nenhum corpo intermediário manifesto, $B$. Assim, se a $C$ [Lua] se atribui $B$, não ser capaz de fazer sombra não havendo nenhum corpo intermediário, e se a $B$ se atribui $A$, o eclipsar-se, é evidente que ocorre eclipse, mas ainda não é evidente por que, e sabemos que existe eclipse, mas não 
sabemos o que ele é. [iii] Mas, estando evidente que $A$ [eclipse] se atribui a $C$ [lua], procurar saber "por que se atribui?" é procurar saber o que é $B$, se é encobrimento, ou rotação da lua, ou extinção. E isso é a definição do outro extremo, isto é, nesses casos, de $A$ [=eclipse]; pois o eclipse é encobrimento pela Terra. ${ }^{36}$ (93a 35-93b 7)

Essa passagem desenvolve o cenário (que é mencionado ao final da seção [i], e que lembra o primeiro caminho) em que se vem a conhecer em estágios distintos, não simultaneamente, o fato de que eclipse existe e a razão por que existe eclipse. A seção [ii] descreve como o investigador passa do estágio 1 para o estágio 2 usando, como ponto de partida, a seguinte definição: o eclipse, se existe, é a incapacidade da Lua cheia de projetar sombra na Terra sem estar obstruída por algum corpo intermediário. Essa definição é diferente das duas primeiras porque ela identifica, em vez de uma parte da essência, uma propriedade que, no final das contas, é um concomitante per se. (Lembra que um concomitante per se é uma propriedade necessária, mas não-essencial, da coisa, propriedade que é explicada pela essência dessa coisa). O investigador procura saber se existe eclipse examinando se existe o fenômeno descrito em sua definição. Assim que ele descobre que existe, ele pode construir o silogismo que Aristóteles formula na seção [ii]:

Eclipse se atribui à incapacidade (da Lua cheia) de projetar sombra na Terra sem estar obstruída por algum corpo.

Incapacidade (da Lua cheia) de projetar sombra na Terra sem estar obstruída por algum corpo se atribui à Lua.

Logo, eclipse se atribui à Lua.

O investigador chegara ao estágio 2: a conclusão afirma que o eclipse existe. Além disso, ele sabe que o eclipse existe enquanto explanandum, porque ele identifica eclipse com um fenômeno que requer explicação. Com base em suas observações (e talvez por coletar testemunhos confiáveis), ele pode inferir que a incapacidade da Lua cheia de projetar sombra, quando não obstruída por algum corpo, não é um evento casual, mas uma ocorrência regular que requer uma explicação - e o mesmo vale para o eclipse.

Esse caminho para o estágio 2 evita o paradoxo do Mênon de um 
modo inusitado. Aristóteles agora deixa de lado a pressuposição em termos de "tudo ou nada" e nega a segunda premisa do paradoxo:

(2) Se não conhecemos o que a causa ou essência de $x$ é, não podemos investigar se existe uma causa ou essência de $x$.

$\mathrm{O}$ texto $\mathrm{T} 5$ torna claro que, mesmo se o investigador não conhece de modo algum o que a essência do eclipse é, ele ainda pode investigar se o eclipse tem uma essência: ele pode começar com uma noção preliminar que identifica o eclipse por uma propriedade que é um concomitante per se. Quando ele estabelece que essa propriedade existe, ele sabe que uma essência existe. Pois ele pode ter certeza de que há uma causa que explica a existência de tal propriedade - e a essência é justamente essa causa.

A seção T5[iii] sugere que o investigador alcança o estágio 3 de modo similar ao que ocorre no primeiro caminho. Ele toma a segunda premissa de seu silogismo e procura por um termo médio que expresse a causa pela qual a Lua é incapaz de projetar sombra. É de se esperar que ele descubra que a causa próxima é que a Lua perdeu sua luminosidade. Essa descoberta pode ser representada no seguinte silogismo:

Incapacidade de projetar sombra, quando não obstruída, se atribui à privação de luz.

Privação de luz se atribui à Lua.

Logo, incapacidade de projetar sombra, quando não obstruída, se atribui à Lua.

O investigador deu um passo decisivo em direção ao conhecimento da essência do eclipse. Ele identificou um outro fenômeno (a privação de luz da Lua) que ocorre durante um eclipse e que explica o fenômeno pelo qual ele iniciou sua investigação. Mas agora ele pode olhar novamente para sua segunda premissa e perguntar:"por que a Lua está privada de luz?”. Novamente, ele pode descobrir a causa: o encobrimento pela Terra.

Privação de luz se atribui ao encobrimento pela Terra.

Encobrimento pela se atribui à Lua.

Logo, privação de luz se atribui à Lua.

Temos, agora, a mesma demonstração reveladora da essência que o inves- 
tigador descobrira no primeiro caminho em direção ao conhecimento. Assim, o investigador, no terceiro caminho, vem a conhecer a essência do eclipse (contanto que ele confronte a essência com um amplo leque de concomitantes per se do eclipse, do modo como discuti antes). Sua investigação está completa. Além disso, ele procedeu, de modo apropriado, daquilo que lhe era mais familiar para aquilo que é mais familiar por natureza: da ausência de sombras na Terra, para a privação de luz na Lua, e para a interposição da Terra. Finalmente, o terceiro caminho em direção ao conhecimento ilustra a tese de Aristóteles no texto T2: o conhecimento prévio de concomitantes per se dá grande contribuição para vir a conhecer a essência.

\section{Conclusão}

Assim se conclui minha interpretação dos três caminhos para o conhecimento em $A P o$ II 8 . Se minha leitura está na direção correta, uma das principais lições filosóficas desse capítulo consiste em estabelecer que o ponto de partida de uma investigação desempenha papel decisivo na determinação de seu sucesso. Aristóteles às vezes é tido como um otimista ingênuo a respeito de nossa capacidade de adquirir conhecimento científico. No entanto, leitura apurada de $A P o$ II 8 mostra que ele é, na verdade, bem cuidadoso: ele julga que a investigação pode ser bem sucedida, mas apenas se ela assume o ponto de partida correto. Que Aristóteles julga ter mostrado como uma investigação bem sucedida procede, e como ela faz uso do silogismo e da demonstração, é evidente por sua conclusão nesse capítulo:

T6 Está dito, portanto, de que modo apreende-se o "o que é" e de que modo ele se torna conhecido, tal que, do "o que é", não há nem silogismo nem demonstração, embora ele se torne evidente através de silogismo e demonstração. ${ }^{37}$ (93b 15-8).

\footnotetext{
${ }^{1}$ Ver Ackrill 1981: 364-7, Bayer [1995, 246], Bolton [1976, 516], Charles [2000, 76], Goldin [1996, 113].

2 Charles 2000: 76, menciona, mas apenas brevemente, a “versão existencial” do impasse.
} 
${ }^{3}$ Ver também 93a 16-20, 92b 4-5, $92 \mathrm{~b} 17$.

4 Charles 2000: capítulos 2 e 3. Embora minha proposta deva muito à discussão feita por Charles, proponho um modo diferente de construir os três estágios, bem como um modo diferente de aplicar esse quadro de três estágios a $A P o$ II 8.

${ }^{5}$ Ver Upton 1991.

6 Cf. White 1994: 154-5.

7 Cf. Ackrill 1981: 364; McKirahan 1992: 190.

8 Cf. Mênon 80d5-8: "Como você irá procurar, Sócrates, se você não sabe de modo algum o que é isso? Qual das coisas que você não conhece você estabelecerá como alvo da sua investigação? E ainda que você efetivamente se depare com ele, como você saberá que era a coisa que você não conhecia?” (Tradução a partir da tradução de Day, utilizada pelo autor).

9 Cf. Mênon 80e 1-5.

10 Este argumento é estruturalmente similar ao dilema que Sócrates apresenta em Mênon, 80e1-5, embora os dois argumentos não sejam idênticos. De fato, o impasse no Mênon não focaliza a possibilidade de procurar pela existência de algo. Antes, o contexto em que o impasse é introduzido sugere que ele se intersse em investigar o que algo é - de fato, Sócrates e Mênon procuram saber o que a virtude é. A concepção aristotélica de investigação também pode originar esse impasse, mas nesse caso a preocupação tem por foco a passagem do estágio 2 para o estágio 3. Por essa razão, este segundo impasse é menos urgente que o primeiro que formulei, pois, se não podemos nem sequer chegar no estágio 2, é claro que a fortiori tampouco podemos chegar no estágio 3. Minha explicação sobre as três vias para o conhecimento segundo $A P o$ II 8 esclarecerá como passamos por todos os três estágios de investigação.

11 Compare-se com o papel que o paradoxo parmenidiano do devir desempenha na teoria aristotélica sobre os princípios do devir em Física I 8.

12 APo II 2, 90a14-23, 31-4; II 8, 93a 3-4; II 10, 94a 3-7. Trata-se da chamada "causa formal". Aristóteles também reconhece a existência de causas materiais, eficientes e finais (Física II 3 and 7, APo II 11). Para os propósitos da demonstração e conhecimento científico, a causa formal (ou essência) é a mais importante. Pois conhecer cientificamente que todo A é B consiste em conhecer que todo A é B devido a $\mathrm{C}$, em que $\mathrm{C}$, o termo médio da demonstração, é a essência de A ( $A P_{0}$ II 17, 99a 21-2). De modo mais geral, as premissas de uma demonstração (a partir das quais obtemos conhecimento científico) são definições, que enunciam essências (cf. APo I 8, 75b 31, II 3, 90 b 25, II 13, 96b 22). Portanto, demonstração e conhecimento científico envolve conhecimento da causa formal ou essência. Com relação às coisas naturais, Aristóteles nota que as causas formais, finais e eficientes muitas vezes são idênticas entre si (Física II 7, 198a 24-6).

13 Física II 5, $196 \mathrm{~b} 10$ ss., 197a 20-1.

${ }^{14}$ Ver $A P o$ I 30. Para discussão útil sobre o significado de "sempre e no mais das vezes", ver Judson 1991.

${ }^{15}$ Ver Ackrill 1981: 376 ss.

doispontos, Curitiba, São Carlos, vol. 7, n. 3 - especial, p.107-130, abril, 2010 
16 Isso envolve uma dificuldade para casos como o eclipse. De fato, eclipses não ocorrem freqüentemente. Em que sentido eles ocorrem sempre ou no mais das vezes? Talvez o grau de freqüência não precise ser muito alto: basta que eclipses ocorram com certa regularidade. Outra possibilidade é que eclipses existam "sempre" no seguinte sentido: sempre que a lua cheia sofre a interposição da Terra entre ela e o Sol, ela perde sua luminosidade. Mas, é claro, a lua cheia nem sempre sofre tal interposição da Terra. Parece que é isso que Aristóteles quer dizer em $A P_{0}$ I 8, 75b 33-6, embora o texto seja difícil de interpretar. (Agradeço a Lucas Angioni pela discussão sobre esse ponto).

17 Ver, por exemplo, Bolton 1987: 130-46, cuja interpretação a respeito de $A P o$ II 8 não explica, ao menos até onde vejo, como o investigador apreende pela primeira vez que um objeto existe. (Ver também Bolton 1976: 521-4, 535.) A interpretação de Mansion 1976: 183 ss., também é problemática, embora sutil e interessante. Ela surpreendemente identifica duas tarefas: vir a conhecer que o objeto existe e vir a conhecer sua essência. Parece-me que essa opinião não pode estar correta, dado que Aristóteles repetidamente insiste que conhecemos que um objeto existe antes de procurar sua essência. Minha interpretação é mais próxima a de Charles 2000: capítulos 2 e 3, e Demoss \& Devereux 1988. Esses comentadores estão muito mais interessados na natureza da definição (o que conta como uma definição, o que não conta, e por que); de minha parte, estou mais interessado em mostrar como a concepção aristotélica de investigação em $A P o$ II 8 responde a uma versão do paradoxo de Mênon.

18 93a 15-29

19 As traduções foram feitas do grego para o inglês por David Bronstein. A tradução do inglês para o português teve como parâmetro a tradução de Lucas Angioni (2004), em confronto com o texto grego, e as discrepâncias foram discutidas entre autor e tradutor (Nota do tradutor).

${ }^{20}$ Este ponto é amplamente admitido. Para discussão de uma interpretação divergente, ver Ackrill 1981: 371-3.

${ }^{21}$ Ver Charles 2000: 23-56; Demoss \& Devereux 1988: 134-5.

22 Cf. Charles 2000: 35-7.

23 É razoável supor que alguns investigadores, no estágio 1, saberiam que o eclipse existe no sentido ordinário (por exemplo, por ouvir dizer) sem ter o tipo de conhecimento que eles virão a adquirir quando passaram ao estágio 2 . Se fizermos uma distinção entre (i) conhecimento ordinário de que o eclipse existe e (ii) conhecimento de estágio 2 de que o eclipse existe como explanandum, poderemos admitir um amplo espectro de estados epistêmicos que seriam característicos dos investigadores no estágio 1.

24 Cf. Goldin 1996: 122-5.

25 A saber, em 93b 7-14: “O que é trovão? Extinção do fogo na nuvem. Por que troveja? Por extinguir-se o fogo na nuvem. Nuvem $C$, trovão $A$, extinção do fogo $B$. Com efeito, a $C$, à nuvem, se atribui $B$ (pois nela extingue-se o fogo), e a este, se atribui $A$, estrondo; e $B$, precisamente, é definição do primeiro extremo, $A$ ”. Ver nota 28. Para interessante discussão dessa 
passagem, ver Bolton 1987: 138-9.

26 Barnes 1993: 219.

27 Esse é um dos tipos de definição que Aristóteles discute em APo II 10: "um tipo de demonstração do 'o que é', diferindo da demonstração no arranjo dos termos (94a 1-2; ver também 94a 12-3).

28 Isso se confirma por uma passagem em APo II 10: "barulho nas nuvens é uma definição de trovão, e essa é a conclusão da demonstração do 'o que é"” (94a 7-9). "Barulho nas nuvens" é um dos exemplos que Aristóteles fornece de parte de uma essência em T1. Trata-se de uma fórmula preliminar, usada para iniciar uma busca pela existência e pela essência do trovão. Quando Aristóteles diz que se trata da "conclusão da demonstração do 'o que é"”, ele sem dúvida refere-se à demonstração que mostra a essência em APo II 8. Observe-se que a conclusão da demonstração é o definiens "barulho nas nuvens" ("barulho ocorre às nuvens"), mas não a proposição em que o definiens é predicado do definiendum, "trovão é barulho nas nuvens" (ver Goldin 1996: 133, n.63). De fato, o termo-sujeito desta última proposição é “trovão", que não pode ser derivado como conclusão de uma demonstração cujo sujeito (ou termo menor) seja "nuvem", como ocorre na demonstração introduzida em 93b 7-14 (ver nota 25 supra). Isso também explica por que, em 93b 7-14, "barulho" substitui "trovão" como predicado ou termo maior. Se isso não ocorresse, a conclusão seria "trovão ocorre às nuvens" e, neste caso, a demonstração não revelaria a essência completa do trovão. Além do mais, essa sentença não é a conclusão a que Aristóteles se refere na passagem de $A P_{0}$ II 10 , tampouco poderia ser a noção preliminar de trovão útil para iniciar uma pesquisa pela sua existência e essência. O ponto principal é o seguinte: o definiendum (trovão, eclipse) não pode ser um termo na demonstração que revela sua essência completa. Para uma interpretação diferente, ver Charles 2000: 198 ss.

29 Texto de Ross.

${ }^{30}$ Esses rótulos modernos se aplicam a Aristóteles apenas imperfeitamente. Na epistemologia contemporânea, fundacionalismo e coerentismo são teorias rivais no terreno da justificação. No entanto, a teoria do conhecimento de Aristóteles dá lugar de honra à explicação, não à justificação. Uma das razões dessa discrepância é que Aristóteles está interessado em um tipo bem específico de conhecimento, a saber, o conhecimento científico - ou o que alguns comentadores preferem chamar de entendimento. Para discussão desse ponto Burnyeat 1981.

31 Ver Metafísica 1029b 1-8. Para discussão, ver Bolton 1976: 529-30; Mansion 1979.

32 Texto de Ross.

33 A interpretação de Ross 1949: 631, nesse passo, é incorreta. Ross supõe que o investigador em T3 não só conhece como aprende que o eclipse existe. Mas é claro que isso não pode ser o caso.

${ }^{34}$ Trata-se de modo pouco ortodoxo de ler a passagem. A intepretação mais aceita (mais bem representada por Charles 2000: 37, mas ver também Barnes 1993: 219-20, e Ross 1949: 631) é que a concepção preliminar do investigador, em T3, é a mesma que me T1: "privação de luz", mas não "interposição da Terra". Mas há três problemas com essa leitura. Primeiro, a seção T3[i] sugere fortemente que há uma mudança na noção preliminar do investigador. Em 
segundo lugar, sem essa mudança, o texto seria desnorteante: Aristóteles definiria o termo B em T3[i] como "interposição" apenas para expurgar seu sentido na seção [ii]. Pois, de acordo com a leitura usual, devemos ler a seção [ii] como se dissesse que procuramos saber se existe um termo B (não-sabemos-o-quê), mas não, como seria mais natural supor, que procuramos saber se existe o termo B como definido na seção [i] (minha leitura). Em terceiro lugar, defensores da leitura usual não explicam como poderíamos descobrir que existe uma causa pela qual a Lua perde sua luminosidade (que é a noção preliminar, na leitura usual) sem ao mesmo tempo vir a saber $o$ que essa causa é. Mas, nesse caso, não poderíamos passar ao estágio $2 \mathrm{sem}$ ao mesmo tempo passar ao estágio 3. Aristóteles julga que esse passo simultâneo ocorre ocasionamente. Mas a leitura tradicional faz dela a regra, não uma exceção.

35 Texto de Ross.

36 Texto de Ross.

37 Texto de Ross.

\section{Referências bibliográficas}

ACKRILL, J.L. (1981). “Aristotle's Theory of Definition: Some Questions on Posterior Analytics II 8-10" in Berti (1981).

BARNES, Jonathan (1993). Aristotle: Posterior Analytics. Translated with a commentary. Second edition. Oxford: Clarendon Press, 1993.

BAYER, Greg (1995). "Definition through Demonstration: The Two Types of Syllogisms in Posterior Analytics II.8" Phronesis 40: 241-264.

BERTI, E. (ed.) (1981). Aristotle on Science: The Posterior Analytics. Proceedings of the Eighth Symposium Aristotelicum. Padua: Antenore.

BOLTON, Robert (1976). "Essentialism and Semantic Theory in Aristotle: Posterior Analytics, II, 7-10" The Philosophical Review 85: 514544.

BOLTON, Robert (1987). "Definition and Scientific Method in Aristotle's Posterior Analytics and Generation of Animals" in Gotthelf and Lennox, Philosophical Issues in Aristotle's Biology, Cambridge: Cambridge University Press, 1987.

BURNYEAT, M.F. (1981). “Aristotle on Understanding Knowledge” in Berti (1981).

CHARLES, David (2000). Aristotle on Meaning and Essence. Oxford: 
Clarendon Press.

DAY, Jane (ed.) (1994). Plato's Meno in Focus. London: Routledge.

DeMOSS, D. and D. Devereux (1988). "Essence, Existence, and Nominal Definition in Aristotle's Posterior Analytics II 8-10" Phronesis 33: 133-154.

JUDSON, Lindsay (1991). "Chance and 'Always or For the Most Part' in Aristotle" in Aristotle's Physics: A Collection of Essays. Ed. Lindsay Judson. Oxford: Clarendon Press.

GOLDIN, Owen (1996). Explaining an Eclipse: Aristotle's Posterior Analytics 2.1-10. University of Michigan Press.

MANSION, Suzanne (1976). Le jugement d'existence chez Aristote. (Second edition, revised and augmented. First published 1946.) Louvain: Éditions de l'Institut Supérieur de Philosophie.

MANSION, Suzanne (1979)."“Plus connu en soi,' "plus connu pour nous.' Une distinction épistémologique importante chez Aristote." Pensamiento (35): 161-70.

McKIRAHAN, Richard (1992). Principles and Proofs: Aristotle's Theory of Demonstrative Science. Princeton: Princeton University Press.

ROSS, W.D. (1949). Aristotle: Prior and Posterior Analytics. A Revised Text with Introduction and Commentary. Oxford: Clarendon Press, 1949.

UPTON, Thomas V. (1991). “The If-It-Is Question in Aristotle” Ancient Philosophy 11: 15-330.

WHITE, Nicholas P. (1994). “Inquiry” in Day (1994). 